\title{
Active White Space (AWS) in Logo Designs: Effects on Logo Evaluations and Brand Communication
}

\author{
Nazuk Sharma \\ Fairfield University, nsharma@fairfield.edu \\ Sajeev Varki
}

Follow this and additional works at: https://digitalcommons.fairfield.edu/business-facultypubs Copyright 2018 Taylor \& Francis for American Academy of Advertising This is an Accepted Manuscript of an article published by Taylor \& Francis in Journal of Advertising in June 2018, available online: http://www.tandfonline.com/10.1080/ 00913367.2018.1463880.

The author post-print has been archived here with permission from the copyright holder.

\section{Peer Reviewed}

\section{Repository Citation}

Sharma, Nazuk and Varki, Sajeev, "Active White Space (AWS) in Logo Designs: Effects on Logo Evaluations and Brand Communication" (2018). Business Faculty Publications. 225.

https://digitalcommons.fairfield.edu/business-facultypubs/225

\section{Published Citation}

Sharma, Nazuk, and Sajeev Varki. "Active White Space (AWS) in Logo Designs: Effects on Logo Evaluations and Brand Communication." Journal of Advertising 47, no.3 (2018): 1-12. https://doi.org/10.1080/ 00913367.2018.1463880.

This item has been accepted for inclusion in DigitalCommons@Fairfield by an authorized administrator of DigitalCommons@Fairfield. It is brought to you by DigitalCommons@Fairfield with permission from the rightsholder(s) and is protected by copyright and/or related rights. You are free to use this item in any way that is permitted by the copyright and related rights legislation that applies to your use. For other uses, you need to obtain permission from the rights-holder(s) directly, unless additional rights are indicated by a Creative Commons license in the record and/or on the work itself. For more information, please contact digitalcommons@fairfield.edu. 


\section{Active White Space (AWS) in Logo Designs: Effects on Logo Evaluations and Brand Communication}

In this paper, we explore Active White Space (AWS) (space between individual logo design elements) as a stylistic modification that revamps a logo design, yet preserves its extant associations. Across three studies, we find AWS to be an effective stylistic logo tool. In Study 1, we find that adding AWS to pictorial logos improves their visual evaluation. In Study 2, we find this positive evaluation to spill-over to verbal brand aspects such that logo designs with AWS are perceived to communicate brand descriptions more clearly. In Study 3, we find that logo designs with AWS benefit sophisticated brand personalities the most followed by sincere, exciting, and competent brand personalities, with no effect on rugged brand personalities. 
Logos are high-value firm assets that impact a firm's performance (Henderson and Cote 1998; Park et al. 2013). A logo as "a graphic design that is used as a continuing symbol for a company, organization, or brand" (AMA 2017) fosters brand identity through recognition and by differentiating it from its competitors (Henderson and Cote 1998; Keller 2008). Advertising research shows that even stylistic changes (where the core design elements remain the same Peracchio and Meyers-Levy 2005) can impact consumer perceptions (Sharma 2016). Similarly, in logo research, stylistic manipulations such as tilting a logo has been found to add perceptions of movement, thereby increasing consumer visual engagement (Cian, Krishna, and Elder 2014). In this research, we examine adding Active White Space (AWS) to a logo (see Figure 1) as another stylistic manipulation.

\section{INSERT FIGURE 1 HERE}

AWS is forwarded by design practitioners as the space between design elements, in contrast to Passive White Space (PWS), i.e., the space around a design (see Figure 1) (Boulton 2007; Turnbull 2011). Prior advertising research shows that adding Passive White Space, PWS (i.e., 'structural space around the ad elements such as between the margins or borders') improves perceptions of product quality and brand prestige (Pracejus, Olsen, and O'Guinn 2006). In addition to improving design aesthetics, PWS is believed to invoke perceptions of extravagance by signaling higher advertising spends and effort (Ambler and Hollier 2004; Kirmani 1990). While prior research has looked at PWS, the merits of Active White Space (AWS) have not been examined.

A qualitative assessment of brand logos shows a progressive trend towards adding AWS to pictorial logo designs, for example, Starbucks, Google Chrome, NBC, Microsoft, and Adidas. Design practitioners have forwarded some advantages of adding AWS such as improved visual 
clarity of a design's structure and layout (Boulton 2007; Ciripitca 2011), as well as enhanced perceptions of minimalism, sophistication, and luxury (Turnbull 2011). In our paper, we formally investigate some of these claims made by practitioners in how adding AWS to logos improves the visual evaluations of these logo designs (including aspects such as visual clarity, aesthetics, and attractiveness). In addition we explore how well logos with AWS are perceived to communicate a brand's verbal descriptions, as well as their fit with different brand personalities (Aaker 1997). The logos that we focus on are pictorial (non-textual) or stand-alone graphic logo designs, consistent with the broader definition of a logos as symbolic brand representations (AMA 2017; McQuarrie and Phillips 2016).

Prior research suggests that perceptual fluency (i.e., the ease of processing of physical attributes of a stimulus including its surface features and presentation context - (Lee and Labroo 2004)) can be increased by enhancing physical aspects such as stimulus clarity through figureground contrast, which in turn improves judgments of stimulus aesthetics, attractiveness, and affect (Reber, Winkielman, and Schwarz 1998; Reber, Schwarz, and Winkielman 2004). In the studies presented here, we examine the perceptual fluency effects of AWS given that AWS manipulates the physical aspects of the logo design by adding white space between the individual design elements. ${ }^{1,3}$

In Study 1, we examine whether a stylistic change such as AWS can impact the visual evaluations of a logo design (Lee and Labroo 2004; Reber, Winkielman, and Schwarz 1998). ${ }^{3}$ In Study 2, we determine whether the perceptual benefits of adding AWS to a logo also improve brand communication clarity, i.e., the perceived clarity with which a logo design communicates the verbal description of the brand (Keller 2008; Shapiro 1999). In Study 3, we examine which brand personalities identified under the Aaker (1997) framework benefit the most from 
incorporating AWS in their logo designs.

\section{AWS IN LOGO DESIGNS AND PERCEPTUAL FLUENCY}

Considerable research has been done on Passive White Space (PWS), i.e., the undefined white space around a design. For example, PWS has been found to add minimalism characterized by cleanliness and visual balance (Olsen, Pracejus, and O'Guinn 2012; Pracejus, Olsen, and O’Guinn 2006). Presence of PWS draws attention to a design and enhances its noticeability further in cluttered advertising scenarios (Olsen, Pracejus, and O'Guinn 2012). Overall, advertising research suggests that PWS isolates a design, making it cleaner, more aesthetic, sophisticated, and tasteful (Kwan, Dai, and Wyer Jr. 2017; Olsen, Pracejus, and O'Guinn 2012).

In contrast, AWS defines each specific logo element by adding white space between the individual logo design elements (Mauloni 2013). In this context, Hagtvedt's (2011) work can be seen as an example of AWS. Hagtvedt (2011) shows that incompleteness in logo designs (where parts of the characters are left intentionally blank, e.g., CONSUL versus CONSUL) improves perceptions of a firm's innovativeness and lowers perceptions of its trustworthiness. The spaces within the brand names used by Hagtvedt (e.g., CONSUL ) can be considered as AWS.

However, our work differs from Hagtvedt in that his work is limited to typeface logos whereas we investigate the effect of AWS on pictorial logo designs, which are more common and consistent with the typical definition of logos as symbolic brand representations (AMA 2017; Henderson and Cote 1998; McQuarrie and Phillips 2016). Additionally, we examine the effects of adding AWS to logo designs on visual evaluations of the logo designs, brand communication clarity (i.e., the clarity with which logo designs with AWS convey verbal brand descriptions), as well as its differential effect on different brand personalities (Aaker 1997).

Positive visual appraisals of logo designs have been shown to improve consumer logo 
evaluations (Henderson and Cote 1998; Muller, Kocher, and Crettaz 2013; Walsh, Winterich, and Mittal 2010). Adding AWS to a logo outlines, isolates, and delimits each individual logo element, visually leading the observer from one logo element to another, thus providing a cleaner hierarchy or structure to the overall logo design (Ciripitca 2011). Similar to the established positive effects of adding PWS in making a design cleaner, aesthetic, and more tasteful, adding AWS to a logo will make the logo design visually clearer and more aesthetic by separating and surrounding each individual logo element with some white space. Therefore, adding AWS to a logo will improve the visual evaluations of the logo design.

In addition to enhancing a logo's visual assessment, AWS will prompt consumers to seek logo design-closure, thereby increasing the overall positive affect derived in the process (Zhao and Meyer 2007). Prior advertising research shows that moderate amounts of omissions from visuals enhances consumer evaluation and processing fluency (Peracchio and Meyers-Levy 1994; Sengupta and Gorn 2002). In providing the missing visual portions themselves, consumers feel accomplished in resolving the slight visual ambiguity, which enhances their overall affect (Peracchio and Meyers-Levy 1994). Similarly, by slightly separating the individual design elements in the visual space and prompting visual closure, we expect AWS to have a further positive impact on the logo's overall visual evaluations.

Literature under the processing fluency model identifies two specific kinds of fluency mechanisms: perceptual and conceptual (Lee 2002; Lee and Labroo 2004). ${ }^{1}$ Perceptual fluency pertains to the ease of visual processing of a design's physical features, and conceptual fluency reflects the ease of semantic processing of a stimulus (Lee 2002; Lee and Labroo 2004; Shapiro 1999). Perceptual fluency is influenced by the physical attributes of a stimulus including its surface features and presentation context (Lee and Labroo 2004). Since AWS manipulates the 
physical, surface aspects of the logo such as isolating each individual logo design element with white space relative to the background, AWS enhances perceptual fluency of the logo design. ${ }^{1,3}$

Reber, Winkielman, and Schwarz (1998) demonstrate that when perceptual fluency is enhanced using aspects such as visual clarity, the stimuli are evaluated to be more attractive. Reber, Schwarz, and Winkielman (2004) note that not only is perceptual fluency hedonically marked, but it also feeds into the aesthetic appreciation of a stimulus. Overall, perceptual fluency manipulations such as figure-ground contrast that improves visual clarity, stimulus repetition, symmetry, and prototypically have been established as positive influencers of aesthetic judgments (Reber, Schwarz, and Winkielman 2004). Given the stylistic manipulation of the physical aspects of the logo design upon incorporating AWS, we propose that the perceptual fluency effects of adding AWS to a logo will improve the logo's visual evaluations in terms of visual clarity, visual aesthetics, and visual attractiveness. Accordingly, we propose that:

H1: Presence (versus absence) of Active White Space (AWS) in a logo design will improve the logo's visual evaluations.

We run Study 1 to test H1, where we assess the impact of adding AWS to two different logo designs on their visual evaluations using measures such as visual clarity, attractiveness, and aesthetics (Reber, Schwarz, and Winkielman 2004; Shapiro 1999).

\section{EFFECT OF AWS IN LOGO DESIGNS ON BRAND COMMUNICATION CLARITY}

The above discussion examines the effect of AWS for isolated logo designs. However, in many contexts, a brand logo is presented alongside a brand's description. For example, Dropbox places its logo ( ) next to the description "Dropbox simplifies your work, with a central place to access and share files" on its website. In this section, we examine whether the positive effect 
of adding AWS to a logo design holds when the logo is coupled with the brand's verbal description (Keller 2008).

Logo research suggests that a successful logo strategy builds on a design that clearly conveys the brand intended associations to consumers (Henderson and Cote 1998). Therefore, a logo design that enhances the clarity of a brand's given associations (as stated in its verbal description) becomes critical to a firm attempting to foster a coherent brand-image in the minds of consumers (Keller 1993, 2008).

Research on feelings-as-information model shows that affective feelings induced by unrelated factors such as background music (Schwarz 1990; Winkielman et al. 2003) or ambient scents (Spangenberg, Crowley, and Henderson 1996) can be (mis)attributed towards the focal stimulus. Consumers have been shown to rely on their current, momentary affect as an informational source towards decision making (Avnet, Pham, and Stephan 2012). Wadhwa and Zhang (2014) show that rounded price figures lead to experiences of 'feeling right', i.e., affectively positive and perceptually fluent. In all such cases, consumer perceptions are driven by a bottom-up process i.e., perceptual fluency aspects of the stimuli (Lee 2002; Shapiro 1999).

In our context, improved perceptual fluency upon adding AWS to logo design, and the correspondingly generated affect can spillover to other brand aspects such as the brand descriptions. ${ }^{1}$ Incidental affective response has been shown to mediate the effect of fluency on consumer evaluative judgments (Janiszewski 1993; Reber, Schwarz, and Winkielman 2004). Spontaneously generated halo or spillover effects can further impact consumer evaluations positively. For example, Hagtvedt and Patrick (2008) show that the positive impact of presence of visual art (versus non-art) on product packages is mediated by a spillover of luxury perceptions from the art onto the product. Similarly, we propose that the positive affect generated 
from enhanced perceptual fluency due to the addition of AWS to a logo design will positively impact the verbally presented brand associations, such that a logo design with AWS present between the logo elements will be perceived to communicate a brand's description more clearly compared to one without AWS (Keller 2008). Therefore,

H2: Presence (versus absence) of Active White Space (AWS) in a logo design will enhance the perceived clarity of the brand communication.

\section{CONGRUENCY BETWEEN AWS IN LOGO DESIGN AND BRAND PERSONALITY}

Labroo, Dhar, and Schwarz (2008) show that visual stimuli with perceptual features that closely match or are congruent with the given word-primes are evaluated more positively. For example, participants primed with dog-related words evaluated a product package with a dog's image on its label more positively than those primed with cat-related words due to a greater ease in processing of the product's perceptual features (Labroo, Dhar, and Schwarz 2008). Reber, Schwarz, and Winkielman (2004) also posit that matches between visual images and related words can increase aesthetic affect. In this section, we examine whether AWS will have differential positive effects depending upon the underlying brand personality being communicated (Aaker 1997).

A brand's personality is defined as "the set of human characteristics associated with a brand" (Aaker 1997, p. 347). Aaker's framework identifies five specific brand personality dimensions: Sincerity, Excitement, Competence, Sophistication, and Ruggedness (Aaker 1997). A sincere brand is honest and real, an exciting brand is aspirational, imaginative, and creative, a competent brand is intelligent and reliable, a sophisticated brand is good looking, charming, and glamorous, and a rugged brand is outdoorsy and tough (Aaker 1997). 
Given the perceptual, aesthetic benefits of adding AWS to logos, we expect logo designs with added AWS to be most consistent with sophisticated brand personalities (Aaker 1997, 1999). Sophisticated brands help fulfil consumer symbolic needs such as social status, exclusivity, and fashion (Keller 2008; Park, Jaworski, and MacInnis 1986). For instance, sophisticated brands such as Gucci and Burberry are associated with self-expression of upperclass status and aesthetics (Kim and Sung 2013). Similarly, Mercedes-Benz and Rolex symbolize one's wealth, and keenness for luxury and fashion (Park, Milberg, and Lawson 1991). Therefore, AWS in logo designs will be most appropriate for such brand personalities.

Following sophisticated brands, we propose that the presence of AWS in logo designs will also positively complement exciting, sincere, and competent brand personalities. Since incorporating AWS to a logo defines and isolates each individual logo element, the added white space between the logo elements provides dynamism and activeness to the overall logo design (Cian, Krishna, and Elder 2014). This complements the independent, imaginative, creative, and spirited aspects of exciting brands (Aaker 1997).

In prior research, creative directors have mentioned that beyond the aesthetic motives, other reasons for incorporating PWS include communication of brand trust, integrity, reliability, and leadership (Olsen, Pracejus, and O'Guinn 2012). Therefore, logo designs with AWS should match competent brand aspects such as intelligence, reliability, and successfulness, as well as sincere brand aspects of honesty and genuineness (Aaker 1997). Finally, given that rugged brands have the least in common in terms of their toughness and outdoorsy appeal with the perceptual effects of adding AWS to a logo design, we do not foresee AWS to impact rugged brands. Accordingly, we hypothesize that: ${ }^{2}$

H3: Presence (versus absence) of Active White Space (AWS) in a logo design will (a) be 
most consistent with sophisticated brand personalities, (b) positively complement exciting, sincere, and competent brand personalities, and (c) have no impact on rugged brand personalities.

\section{STUDY 1: PERCEPTUAL FLUENCY EFFECTS OF AWS}

The main objective of Study 1 is to test H1, i.e., the effect of adding AWS to a logo design on the logo's visual evaluations. Study 1 manipulates AWS for two different logo designs under a repeated-measures paradigm, and captures the effect of AWS on measures such as visual clarity, attractiveness, and aesthetics. Additionally, we assess changes in perceptual fluency based upon adding AWS in logo designs via the changes in consumer perceived design familiarity with the unknown logos employed in this study. ${ }^{3}$

Research on processing fluency model and mere exposure effects evidences that stimulus repetitions increase consumer evaluations by generating feelings of stimulus familiarity (Janiszewski 1993; Lee and Labroo 2004; Zajonc 1968). The relative ease of stimulus recognition on subsequent exposures and enhanced familiarity is attributed to perceptual fluency, i.e., the processing of the stimulus's physical features (Lee and Labroo 2004; Whittlesea, Jacoby, and Girard 1990). Whittlesea (1993) shows that feelings of familiarity can be induced even in the absence of a prior exposure, when the processing of the stimulus is perceptually fluent. Therefore, we use changes in perceived familiarity of unknown logo designs when presented with (versus without) AWS as a manipulation check in this study. ${ }^{3}$

\section{Study 1: Method}

Seventy-two MTurk respondents (51\% males, 49\% females, $M_{\mathrm{age}}=35$ years) participated in exchange for compensation (\$.25) in a mixed study design with AWS manipulated between- 
subjects (AWS: present vs absent), and two different logo designs presented (one at a time) within-subjects (see Appendix 1). Upon viewing each logo (presented in random order), subjects rated the logo designs on measures such as visual clarity, visual attractiveness, and visual aesthetics $(1=$ very low to 7 = very high $)($ Labroo, Dhar, and Schwarz 2008; Reber, Schwarz, and Winkielman 2004; Reber, Winkielman, and Schwarz 1998). A visual evaluation score was calculated for each logo by taking an average of the three aforementioned items for each logo $\operatorname{design}\left(r_{\log 01}=.91, r_{\log 02}=.86\right)$.

Participants also reported their overall attention to the two logo designs presented in the survey $(1=$ skimmed them quickly to $7=$ paid a lot of attention, $1=$ not at all involved with the designs to $7=$ very involved with the designs, $1=$ not at all engaged with the designs to $7=$ very engaged with the designs, $r=.91)$. The overall reported attention to the logo designs $(M=5.97)$ did not differ across conditions $(p>.10)$. Finally, they reported their overall familiarity with the two logo designs on a 7-point scale (Henderson and Cote 1998; Janiszewski and Meyvis 2001; Lee and Labroo 2004), followed by gender and age demographics. Gender and age had no impact in any study, and hence are not discussed further.

\section{Study 1: Findings}

For the manipulation check, participants reported a significantly higher sense of familiarity with the evaluated logo designs in the presence of AWS compared to its absence from the logo designs $\left(F(1,70)=4.82, p<.05 ; M_{\text {AWS-present }}=4.30, M_{\text {AWS-absent }}=3.40, M_{\text {difference }}=.90\right.$, $p<.05$ ). Logo design familiarity was higher in the presence (versus absence) of AWS, even though the designs were self-created by the authors suggesting an induced sense of familiarity. Thus, the manipulation check on AWS acting a perceptual fluency effect on logo designs was successful. 
A repeated-measures ANOVA with AWS (presence versus absence) as the betweensubjects factor, logo type as the repeated-measure, and visual logo evaluations as the dependent variable revealed a significant main effect of AWS, a significant main effect of logo type, but no significant interaction between AWS and the logo type $(p>.10)$. The first logo was evaluated higher on the logo evaluation measures compared to the second design $\left(M_{\text {difference }}=.57, p<.05\right)$. However, focal to our hypothesis, both logo designs were overall assessed more favorably on visual aspects in the presence of AWS compared to its absence from the logo designs $(F(1,70)$ $\left.=4.82, p<.05 ; M_{\mathrm{AWS}-\text { present }}=4.63, M_{\mathrm{AWS}-\mathrm{absent}}=4.01, M_{\text {difference }}=.62, p<.05\right)$. This supports $\mathrm{H} 1$ (see Table 1).

\section{INSERT TABLE 1 HERE}

\section{STUDY 2: AWS AND BRAND COMMUNICATION CLARITY}

Study 1 looked at the perceptual fluency effects of adding AWS to isolated logo designs. In Study 2, we assess how AWS affects brand communication clarity when the logo (with versus without AWS) is presented alongside verbal brand descriptions (see H2).

\section{Study 2a: Method}

Sixty-three undergraduate students $\left(37 \%\right.$ males, $63 \%$ females, $M_{\text {age }}=24$ years $)$ at a large southern university participated in a single factor, two-level (AWS: present versus absent), between-subjects design in exchange for extra course credit. A fictitious company (Sano) was verbally described as a brand offering furniture products (adapted from the 'About Us' section of a real furniture brand) with a chair-emulating logo design (see description in Appendix 2). AWS was manipulated between-subjects. Students were randomly assigned to either AWS-present or AWS-absent conditions and asked to assess the brand logo using a paper and pencil format. 
Participants in each condition (AWS: present versus absent) completed measures on how well they thought the logo design communicated the brand's offerings $(1=$ unclearly to $7=$ clearly; $1=$ vaguely to $7=$ vividly; $1=$ ambiguously to $7=$ unambiguously) $($ Hagtvedt 2011 ; Henderson and Cote 1998; Janiszewski and Meyvis 2001). These measures were averaged to create a brand communication clarity score $(r=.95)$. Perceptions regarding logo design complexity were also captured (Rahinel and Nelson 2016; Song and Schwarz 2008). Design complexity $(M=4.00)$ did not differ across the two conditions $(p>.10)$. Participants finished by reporting their familiarity regarding the brand name $(1=$ highly unfamiliar to $6=$ highly familiar $)$ $(M=2.03)$, gender and age.

\section{Study 2a: Findings}

A one-way ANOVA with AWS as the between-subjects factor revealed a significant main effect of the presence (versus absence) of AWS in the logo design on brand communication clarity $(F(1,61)=4.42, p<.05)$. Reported clarity of the brand description as communicated through the logo design was significantly higher in the presence of AWS compared to its absence $\left(M_{A W S-\text { present }}=5.73, M_{A W S \text {-absent }}=5.08 ; M_{\text {difference }}=.65, p<.05\right)$. This provides support to $\mathrm{H} 2$.

\section{Study 2b: Method}

In Study 2a, the primary logo shape can be characterized as angular. Research on logo designs suggests that rounded versus angular logo shapes could impact brand perceptions differentially (Jiang et al. 2016; Lieven et al. 2015). For example, rounded (versus angular) logos are considered to enhance perceptions of softness resulting in the company being perceived as more consumer sensitive (Jiang et al. 2016). To evidence robustness of our proposed positive effect of AWS on brand communication clarity regardless of logo shape, Study $2 \mathrm{~b}$ employed a mixed-design with AWS manipulated between-subjects and two logo shapes (rounded and 
angular) presented within-subjects (see Appendix 3).

Fifty-eight undergraduate students (63\% males, $37 \%$ females, $M_{\text {age }}=25$ years) participated in this paper and pencil study in exchange for extra course credit. They were randomly assigned to either an AWS-present or an AWS-absent condition and asked to evaluate the logo designs that differed in shape across a logistics firm and a packaging firm. One survey response was missing data and was removed, leaving a final dataset of 57.

Participants in each condition (AWS: present versus absent) completed measures on how well the logo designs communicated the brand offerings, presented verbally alongside each logo design $(1=$ unclearly to $7=$ clearly; $1=$ vaguely to $7=$ vividly; $1=$ ambiguously to $7=$ unambiguously) (Hagtvedt 2011, Janiszewski and Meyvis 2001; Lee and Labroo 2004). As in Study $2 \mathrm{a}$, these measures were averaged to create a brand communication clarity score for each $\operatorname{logo}\left(r_{\text {logol }}=.93 ; r_{\log o 2}=.96\right)$. Participants finished by reporting their brand name familiarity, gender, and age $\left(M_{\text {logol }}=1.49\right.$ and $M_{\text {logo } 2}=1.78 ; 1=$ highly unfamiliar, $6=$ highly familiar $)$.

\section{Study 2b: Findings}

A repeated-measures ANOVA with AWS as the between-subjects factor and logo type as the repeated-measures factor revealed only a significant main effect of AWS on brand communication clarity $(F(1,55)=6.34, p<.05)$. The repeated-measures factor (logo type) was neither significant as a main effect nor as an interaction with AWS $(p>.10)$. Across both logo designs, brand communication clarity was significantly higher in the presence of AWS in the logo design relative to its absence $\left(M_{A W S \text {-present }}=4.15, M_{A W S \text {-absent }}=3.28, M_{\text {difference }}=.87, p<.05\right)$. Thus, H2 was reconfirmed (see Table 2).

INSERT TABLE 2 HERE 


\section{STUDY 3: AWS IN LOGOS AND BRAND PERSONALITY}

In Study 3, we examine how presence (versus absence) of AWS in a logo design interacts with a given brand personality (Aaker 1997). In other words, the goal is to investigate how adding AWS to logos differentially impacts different brand personality types (i.e., H3). In Study 3, we employ a 5 (Brand personality: Sincere, Exciting, Competent, Sophisticated, or Rugged) X 2 (AWS: absent followed by present) mixed-design, with brand personality manipulated between-subjects through verbal brand descriptions (five-levels), and each of the five groups exposed to logo designs first with and then without AWS (two-levels), within-subjects.

\section{Study 3: Method}

Pretest. Prior to the main study, we conducted a pretest to ensure that the brand descriptions were indeed conveying the respective brand personalities (Aaker 1997). Participants recruited from Amazon's MTurk $\left(N=53,57 \%\right.$ males, $43 \%$ females, $M_{\text {age }}=36$ years, compensation $=\$ .35)$ were told that Claro is a consulting company $\left(M_{\text {familiarity }}=2.64\right.$ on a 7 point scale) attempting to understand how certain brand descriptions fit the given brand personality classifications (of Aaker 1997), and requested them to help the company match each brand script to its most appropriate brand personality type. Participants were requested to match each of the listed brand descriptions (see Appendix 4) to one of the five brand personality categories shown to them (Sincere, Exciting, Competent, Sophisticated, or Rugged).

Given a $20 \%$ chance of matching a given description to one of the five brand personality types, participants matched each brand description correctly at a rate much greater than $20 \%$. For the sincere brand, 32 out of 53 respondents matched the script to the sincere brand personality $\left(\mathrm{Chi}^{2}=62.00, p<.001\right)$. Thirty-eight out of 53 participants categorized the exciting script to the same brand personality category $\left(\mathrm{Chi}^{2}=89.36, p<.001\right)$. Thirty-five respondents categorized the 
competent script to the corresponding competent category $\left(\mathrm{Chi}^{2}=74.08, p<.001\right)$. Forty respondents matched the sophisticated script to the corresponding personality category $\left(\mathrm{Chi}^{2}=\right.$ $103.89, p<.001)$, and 41 categorized the rugged brand script to the rugged brand category $\left(\mathrm{Chi}^{2}\right.$ $=109.17, p<.001$ ). Hence, these brand scripts were used again (independently) with a logo design and the same brand name in the main study.

Main study. In total, 151 MTurkers participated in the main study (56\% males, $44 \%$ females, $M_{\text {age }}=37$ years, compensation $\left.=\$ .50\right)$ with respondents from the pretest screened-out using their MTurk IDs to ensure data quality and integrity (Goodman, Cryder, and Cheema 2013; Sharpe Wessling, Huber, and Netzer 2017). Participants were randomly assigned to one of the five conditions, each consisting of a logo (initially without AWS) and a pretested brand script from the Sincere, Exciting, Competent, Sophisticated, or Rugged category (see Appendix 4) (Aaker 1997; Sung and Kim 2010). The same logo design was used across all brand personality conditions for pictorial consistency. Participants were then told that the brand they had just evaluated was considering changing its logo design to the one with added AWS. Please note that the target logo design with AWS was presented visually without stating that AWS had been incorporated into the original logo design.

We requested the participants to assess the extent to which they thought the new (target) logo design (with added AWS) matched with the given brand personality compared to the previous logo design (without AWS) on the following six items: "This new logo design matches the brand's personality", "This new logo design is consistent with the brand's personality", "This new logo design fits with the brand's personality", "This new logo design complements the brand's personality", "This new logo design is compatible with the brand's personality", and "This new logo design is congruent with the brand's personality" (-5 = Much less than the 
previous logo design to $+5=$ Much more than the previous logo design; $r=.97)$ (Kim and Sung 2013; Aaker and Lee 2006; Lee, Keller, and Sternthal 2010). Participants finished up by reporting their gender and age.

\section{Study 3: Findings}

Except for rugged brand personality type, there was a significant positive impact of adding AWS to the logo design for each brand personality, as revealed by the one-sample t-test values $(p<.05)$ (see Table 3$)$. As predicted, presence (versus absence) of AWS in a logo design was found to be most consistent with sophisticated brand personality type $(M=2.11, t(1,29)=$ $7.69, p<.001)$. This was followed by a positive effect of AWS in logo designs for sincere $(M=$ $1.20, t(1,27)=3.08, p<.01)$, exciting $(M=.96, t(1,31)=2.10, p<.05)$, and competent brands $(M=.81, t(1,29)=2.50, p<.05)$. There was no effect of adding AWS to rugged brand logo $(p$ $>$.10). Overall, these findings support $\mathrm{H} 3$.

\section{INSERT TABLE 3 HERE}

\section{GENERAL DISCUSSION}

A successful stand-alone pictorial logo is designed not only to foster a visually stimulating brand identity but also to encourage quick recognition by consumers (Henderson and Cote 1998; McQuarrie and Phillips 2016). Research shows that logo redesigns with simple, stylistic modifications such as changing a previously angular logo to a rounded one can lower consumers' brand attitudes, especially for consumers with strong brand commitments (Walsh, Winterich, and Mittal 2010, p. 78; 2011). Conversely, if a firm does not invest in visually rejuvenating its logo, boredom sets in with repeated exposures (Grobert, Cuny, and Fornerino 2016; Muller, Kocher, and Crettaz 2013). Thus, logo redesign is a strategic task where a new 
firm can decide on a fresh brand identity but an established firm cannot deviate too much from its original logo design. Thus, marketers seek a balance between visually revamping a logo while being able to preserve its pre-existing associations.

Our findings show that AWS as a stylistic modification (in that the core logo design elements remain unchanged) can improve visual logo evaluations on accounts of perceptual fluency, while retaining a brand's original logo design elements (Peracchio and Meyers-Levy 2005). We found this effect to hold consistently across different logo types (Study 1).

We also found AWS to positively impact logo designs when coupled with verbal brand descriptions (Studies 2a and 2b). Finally, AWS in logo designs was found to be most fitting with sophisticated brand personalities and to a lesser but significant extent with sincere, exciting, as well as competent brand personalities (Study 3). Given these findings, sophisticated brands such as Rolex and Mercedes-Benz may find it beneficial to incorporate AWS in their logo designs, not only to elevate brand freshness but also to add to their stylish brand-image.

Our research augments the literature on white space, especially in relation to visual logo research (Ambler and Hollier 2004; Olsen, Pracejus, and O'Guinn 2012; Pracejus, Olsen, and O’Guinn 2006; Rand 1993). Designers have informally differentiated 'active' or 'micro' white space from the 'passive' or 'macro' white space (Turnbull 2011). However, to the best of our knowledge, no one has formally studied the perceptual fluency effects of AWS in logo designs on logos' visual evaluations, brand communication clarity, and brand personality types.

However, as with original research, our work has several limitations. Even though we took care to add a symmetrical amount of AWS in our logo designs and attempted to ensure that the overall logo size did not change upon adding AWS, the amount of AWS that could be added to a logo sets a boundary condition for our work. ${ }^{4}$ It would be interesting to explore the extent to 
which AWS can be added till such time that the logo appears visually disconnected and perceptually disfluent (Berlyne 1970). ${ }^{4}$ Additionally, the current studies focus only on the effect of adding AWS to pictorial logo designs. The amount of AWS between the logo design and other brand aspects (such as the brand name) could also make for interesting future research (Kwan, Dai, and Wyer Jr. 2017; McQuarrie and Phillips 2016). ${ }^{4}$

Lack of color in our logo designs serves as another limitation. We kept the logos color neutral to avoid confounds. However, AWS may impact colored logo designs differently (perhaps more positively), compared to those lacking in color (Labrecque and Milne 2012; McQuarrie and Phillips 2016). Single-meaning versus multiple-meanings embedded in a logo design (termed as logo complexity by Janiszewski and Meyvis 2001) can be an interesting moderator to explore as well.

Finally, we employed fictitious logo designs, brand names, and descriptions throughout our studies to maintain clean manipulations. While this was important to gauge the effects solely based upon AWS manipulation, prior (existing) consumer brand associations (Keller 1993, 2008) could reveal interesting differences with respect to perceptual (and possibly conceptual) fluency in future studies. 
Footnote $1-$ We thank reviewer 1 in helping us clarify our focus on perceptual fluency as being affected by the incorporation of AWS in logo designs.

Footnote $2-$ We thank reviewers 2 and 3 in helping us simplify the theoretical aspects of interaction between AWS and brand personality types.

Footnote $3-$ We thank reviewer 3 in helping to clarify that AWS itself is a manipulation of perceptual fluency.

Footnote 4 - We thank reviewer 3 in pointing out these study limitations. 


\section{REFERENCES}

Aaker, Jennifer L (1997), "Dimensions of brand personality." Journal of Marketing

Research, 34(3), 347-356.

(1999), "The Malleable Self: The Role of Self-Expression in Persuasion,"

Journal of Marketing Research, 36(1), 45-57.

Aaker, Jennifer L., and Angela Y. Lee (2006), "Understanding regulatory fit." Journal of Marketing Research, 43(1), 15-19.

AMA (2017), "Dictionary,” American Marketing Association, available at

https://www.ama.org/resources/Pages/Dictionary.aspx.

Ambler, Tim, and Ann E. Hollier (2004), "The Waste in Advertising is the Part that

Works," Journal of Advertising Research, 44(4), 375-389.

Avnet, Tamar, Michel Tuan Pham, and Andrew T. Stephen (2012), "Consumers' trust in feelings as information," Journal of Consumer Research, 39(4), 720-735.

Berlyne, Daniel E. (1970), "Novelty, Complexity, and Hedonic value," Perception \& Psychophysics, 8(5), 279-286.

Boulton, Mark (2007), “Whitespace,” Graphic Design, Layout \& Grids, (230), January 09, available at http://alistapart.com/article/whitespace.

Cian, Luca, Aradhna Krishna, and Ryan S. Elder (2014), "This Logo Moves Me:

Dynamic Imagery from Static Images," Journal of Marketing Research, 51(2), 184-197.

Ciripitca, Corina (2011), "Why is White Space Good for Graphic Design?,” designmodo, October 13, available at http://designmodo.com/white-space-graphic-design/.

Goodman, Joseph K., Cynthia E. Cryder, and Amar Cheema (2013), "Data collection in a flat world: The strengths and weaknesses of Mechanical Turk samples," Journal of Behavioral 
Decision Making, 26(3), 213-224.

Grobert, Julien, Caroline Cuny, Marianela Fornerino, and Francisco Guzman (2016), "Surprise! We Changed the Logo," Journal of Product \& Brand Management, 25(3), 239-246. Hagtvedt, Henrik (2011), "The Impact of Incomplete Typeface Logos on Perceptions of the Firm," Journal of Marketing, 75(4), 86-93.

Hagtvedt, Henrik, and Vanessa M. Patrick (2008), "Art Infusion: The Influence of Visual Art on the Perception and Evaluation of Consumer Products," Journal of Marketing Research, 45(3), 379-389.

Henderson, Pamela W., and Joseph A Cote (1998), "Guidelines for Selecting or Modifying Logos," The Journal of Marketing, 62(2), 14-30.

Janiszewski, Chris (1993), "Preattentive Mere Exposure Effects," Journal of Consumer Research, 20(3), 376-392. , and Tom Meyvis (2001), "Effects of Brand Logo Complexity, Repetition, and Spacing on Processing Fluency and Judgment," Journal of Consumer Research, 28(1), 18-32.

Jiang, Yuwei, Gerald J. Gorn, Maria Galli, and Amitava Chattopadhyay (2016), "Does Your Company Have the Right Logo? How and Why Circular-and Angular-Logo Shapes Influence Brand Attribute Judgments," Journal of Consumer Research, 42(5), 709-726.

Keller, Kevin L (1993), "Conceptualizing, Measuring, and Managing Customer-based Brand Equity," Journal of Marketing, 57(1), 1-22. (2008), "Strategic Brand Management," Pearson Education.

Kim, Dong Hoo, and Yongjun Sung (2013), "Gucci versus Old Navy: Interplay of brand personality and regulatory focus in advertising persuasion," Psychology \& Marketing, 30(12), 1076-1087. 
Kirmani, Amna (1990) "The effect of perceived advertising costs on brand perceptions," Journal of Consumer Research, 17(2), 160-171.

Kwan, Canice MC, Xianchi Dai, and Robert S. Wyer Jr (2017), "Contextual Influences on Message Persuasion: The Effect of Empty Space," Journal of Consumer Research, 44(2), 448-464.

Labrecque, Lauren I., and George R. Milne. (2012) "Exciting Red and Competent Blue: the Importance of Color in Marketing." Journal of the Academy of Marketing Science, 40(5), 711-727.

Labroo, Aparna A., Ravi Dhar, and Norbert Schwarz (2008), "Of frog wines and frowning watches: Semantic priming, perceptual fluency, and brand evaluation." Journal of Consumer Research, 34(6), 819-831.

Lee, Angela Y (2002), "Effects of Implicit Memory on Memory-based Versus Stimulusbased Brand Choice," Journal of Marketing Research, 39(4), 440-454. , and Aparna A. Labroo (2004), "The Effect of Conceptual and Perceptual Fluency on Brand Evaluation," Journal of Marketing Research, 41(2), 151-165.

Lee, Angela Y., Punam Anand Keller, and Brian Sternthal (2010), "Value from regulatory construal fit: The persuasive impact of fit between consumer goals and message concreteness," Journal of Consumer Research 36(5), 735-747.

Lieven, Theo, Bianca Grohmann, Andreas Herrmann, Jan R Landwehr, and Miriam van Tilburg (2015), "The Effect of Brand Design on Brand Gender Perceptions and Brand Preference," European Journal of Marketing, 49(1/2), 146-169.

Mauloni, Mark (2013), "How Important is White Space in Print Design?," Serif Blog, January 7, available at http:/www.serif.com/blog/how-important-is-white-space-in-print-design/. 
McQuarrie, Edward F., and Barbara J. Phillips (2016), "Visual Branding: A Rhetorical and Historical Analysis," Massachusetts, Edward Elgar Publishing, Inc.

Müller, Brigitte, Bruno Kocher, and Antoine Crettaz (2013), "The Effects of Visual Rejuvenation through Brand Logos," Journal of Business Research, 66(1), 82-88.

Olsen, G. Douglas, John W. Pracejus, and Thomas C. O'Guinn (2012), " Print Advertising: White Space," Journal of Business Research, 65(6), 855-860.

Park, C. Whan, Andreas B. Eisingerich, Gratiana Pol, and Jason W. Park (2013), "The Role of Brand Logos in Firm Performance," Journal of Business Research, 66(2), 180-187. , Bernard J. Jaworski, and Deborah J. Maclnnis (1986), "Strategic brand conceptimage management," The Journal of Marketing, 50(4), 135-145. , Sandra Milberg, and Robert Lawson (1991), "Evaluation of brand extensions: the role of product feature similarity and brand concept consistency." Journal of Consumer Research, 18(2), 185-193.

Peracchio, Laura A., and Joan Meyers-Levy (1994), "How Ambiguous Cropped Objects in Ad Photos can Affect Product Evaluations," Journal of Consumer Research, 21(1), 190-204. , and __ (2005), "Using Stylistic Properties of Ad Pictures to Communicate with Consumers," Journal of Consumer Research, 32(1), 29-40.

Pracejus, John W., G. Douglas Olsen, and Thomas C. O’Guinn (2006), " How Nothing became Something: White Space, Rhetoric, History, and Meaning," Journal of Consumer Research, 33(1), 82-90.

Rahinel, Ryan, and Noelle M. Nelson (2016), "When Brand Logos Describe the Environment: Design Instability and the Utility of Safety-Oriented Products," Journal of Consumer Research, 43(3), 478-496. 
Rand, Paul (1993), "Design, Form and Chaos", New York.

Reber, Rolf, Norbert Schwarz, and Piotr Winkielman (2004), "Processing fluency and aesthetic pleasure: Is beauty in the perceiver's processing experience?," Personality and Social Psychology Review, 8(4), 364-382. , Piotr Winkielman, and Norbert Schwarz (1998), "Effects of Perceptual Fluency on Affective Judgments," Psychological Science, 9(1), 45-48.

Schwarz, Norbert (1990), "Feelings as information: informational and motivational functions of affective states," Guilford Press.

Sengupta, Jaideep, and Gerald J. Gorn (2002), "Absence Makes the Mind Grow Sharper: Effects of Element Omission on Subsequent Recall," Journal of Marketing Research, 39(2), 186201.

Shapiro, Stewart (1999), "When an ad's influence is beyond our conscious control: Perceptual and conceptual fluency effects caused by incidental ad exposure," Journal of Consumer Research, 26(1), 16-36.

Sharma, Nazuk (2016), "Luxury implications of showcasing a product with its "cast" shadow," Journal of Consumer Marketing, 33(7), 507-516,

Sharpe Wessling, Kathryn, Joel Huber, and Oded Netzer (2017), "MTurk Character Misrepresentation: Assessment and Solutions," Journal of Consumer Research, 44(1), 211-230.

Song, Hyunjin, and Norbert Schwarz (2008), "If it's Hard to Read, it's Hard to do: Processing Fluency affects Effort Prediction and Motivation," Psychological Science, 19(10), 986-988.

Spangenberg, Eric R., Ayn E. Crowley, and Pamela W. Henderson (1996) "Improving the store environment: do olfactory cues affect evaluations and behaviors?," The Journal of 
Marketing, 60 (2), 67-80.

Sung, Yongjun, and Jooyoung Kim (2010), "Effects of brand personality on brand trust and brand affect," Psychology \& Marketing, 27(7), 639-661.

Turnbull, Connor (2011), "Using White Space (or Negative Space) in Your Designs," envatotuts + web design theory, July 19, available at http://webdesign.tutsplus.com/articles/using-white-space-or-negative-space-in-your-designs-webdesign-3401.

Wadhwa, Monica, and Kuangjie Zhang (2014), "This Number Just Feels Right: The Impact of Roundedness of Price Numbers on Product Evaluations," Journal of Consumer Research, 41(5), 1172-1185.

Walsh, Michael F., Karen P. Winterich, and Vikas Mittal (2010), "Do Logo Redesigns Help or Hurt your Brand? The Role of Brand Commitment," Journal of Product \& Brand Management, 19(2), 76-84. , and __ (2011), "How Re-designing Angular Logos to be Rounded

Shapes Brand Attitude: Consumer Brand Commitment and Self-construal," Journal of Consumer Marketing, 28(6), 438-447.

Whittlesea, Bruce W. A. (1993), “Illusions of Familiarity,” Journal of Experimental Psychology: Learning, Memory, and Cognition, 19(6), 1235-1253. , Larry L. Jacoby, and Krista Girard (1990), “Illusions of Immediate Memory: Evidence of an Attributional Basis for Feelings of Familiarity and Perceptual Quality," Journal of Memory and Language, 29, 716-732.

Winkielman, Piotr, Norbert Schwarz, Tetra Fazendeiro, and Rolf Reber (2003), "The hedonic marking of processing fluency: Implications for evaluative judgment," The Psychology 
of evaluation: Affective processes in cognition and emotion, 189-217.

Zajonc, Robert B. (1968), "Attitudinal effects of mere exposure," Journal of Personality and Social Psychology, 9(2), 1-27.

Zhao, Shenghui, and Robert J. Meyer (2007), "Biases in predicting preferences for the whole visual patterns from product fragments," Journal of Consumer Psychology, 17(4), 292304. 
TABLE 1

Means (and Standard Deviations) for logo evaluations in Study 1

* Visual evaluations for each logo design calculated using an average of three items: visual clarity, visual attractiveness, and visual aesthetics. 
TABLE 2

Means (and Standard Deviations) for Brand Communication Clarity in Study $2 \mathrm{~b}$

11

12

13

14

15

16

17

18

19

20

21

22

23

24

25

26

27

28

29

30

31

32

33

34

35

36

37

38

39

40

41

42

43

44

45

46

47

48

49

50

51

52

53

54

55

56

57

58

59

60 


\section{TABLE 3}

One-sample t-test values for each brand personality upon adding AWS to logos in Study 3

10

\begin{tabular}{lccc}
\hline Brand Personality & One-sample t-test value & $\mathrm{df}$ & $p$ value \\
\hline Sincere $(\mathrm{n}=28)$ & $3.08^{*}$ & 27 & .005 \\
Exciting $(\mathrm{n}=32)$ & $2.10^{*}$ & 31 & .044 \\
Competent $(\mathrm{n}=30)$ & $2.50^{*}$ & 29 & .018 \\
Sophisticated $(\mathrm{n}=30)$ & $7.69^{*}$ & 29 & .000 \\
Rugged $(\mathrm{n}=31)$ & .31 & 30 & .759
\end{tabular}

* Significant at .05 

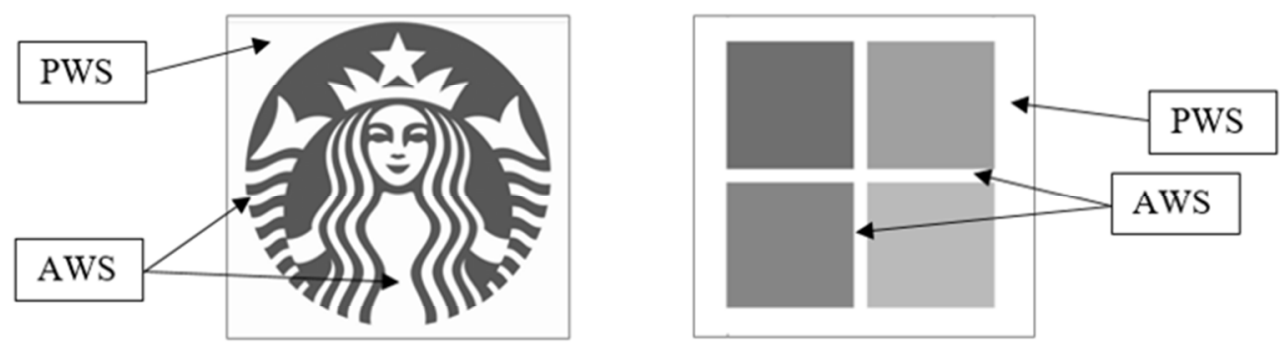

FIG 1. Contemporary logo designs with AWS and PWS

(Starbucks on the left and Microsoft on the right) 


\section{APPENDIX 1}

Stimuli used in Study 1 (Repeated-measures): AWS (Present versus absent)
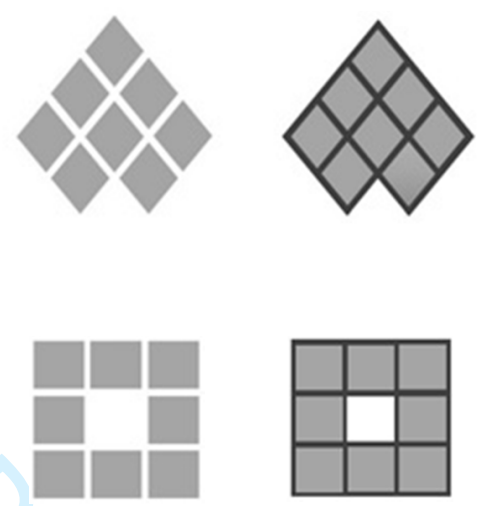
Sano Furniture manufactures high-fashion furniture, and imports an extensive line of wood, bedroom, living room, home office, and leather furniture from around the world. The firm believes in making stylish, beautiful, and well-crafted products.

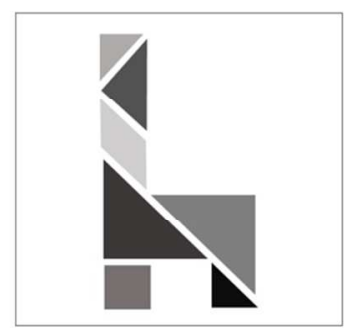

Sano Furniture manufactures high-fashion furniture, and imports an extensive line of wood, bedroom, living room, home office, and leather furniture from around the world. The firm believes in making stylish, beautiful, and well-crafted products.

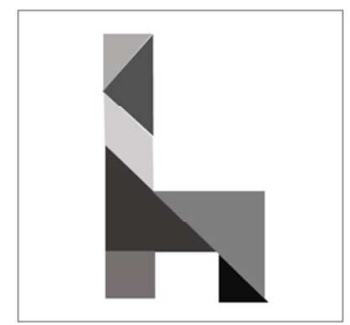




\section{APPENDIX 3}

Stimuli used in Study 2b (Repeated-measures): AWS (Present versus absent)
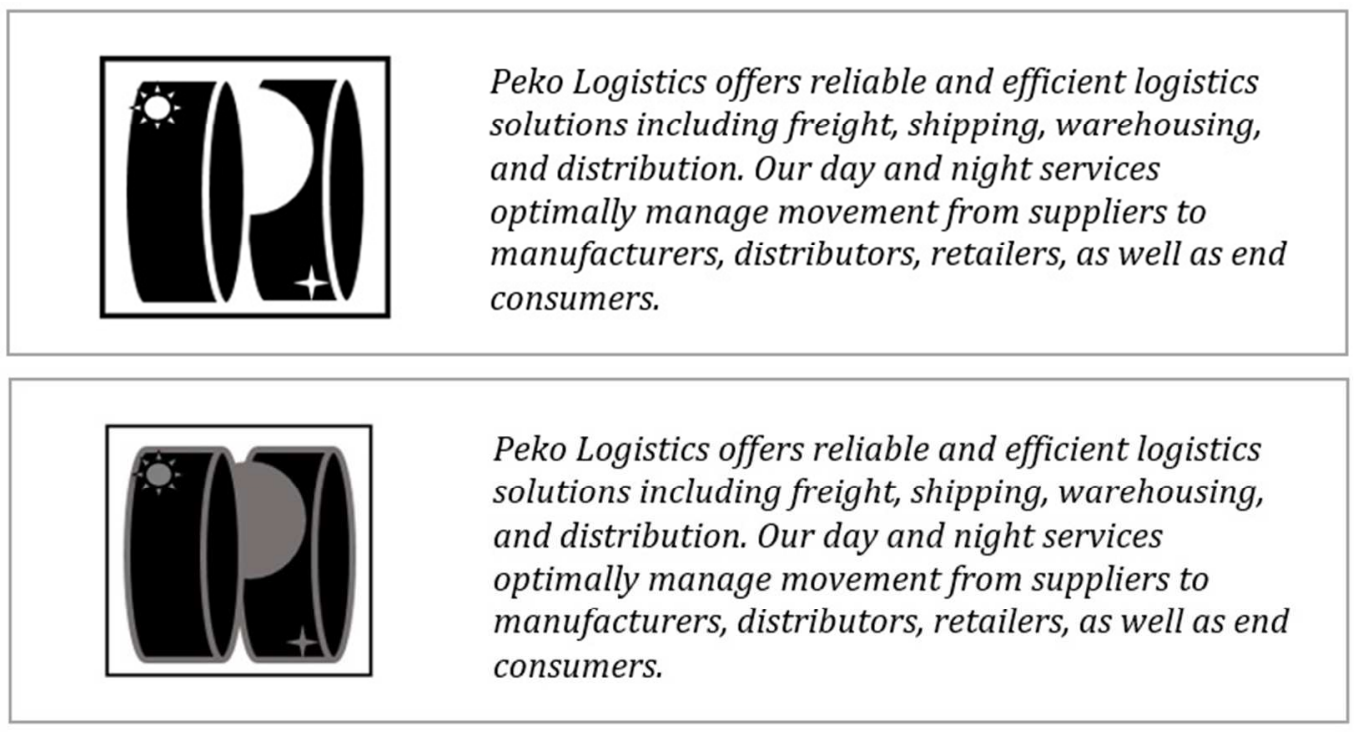

Stihl is a rapidly growing packaging company
providing solutions to commercial businesses. We
build our designs on the premise that packaging
can give products a distinct advantage based on
visual appeal, product protection as well as
consumer convenience.

\section{APPENDIX 4}


Stimuli used in Study 3: Brand personalities (Sincere, Exciting, Competent, Sophisticated, and Rugged) manipulated between-subjects and AWS (Absent followed by present)
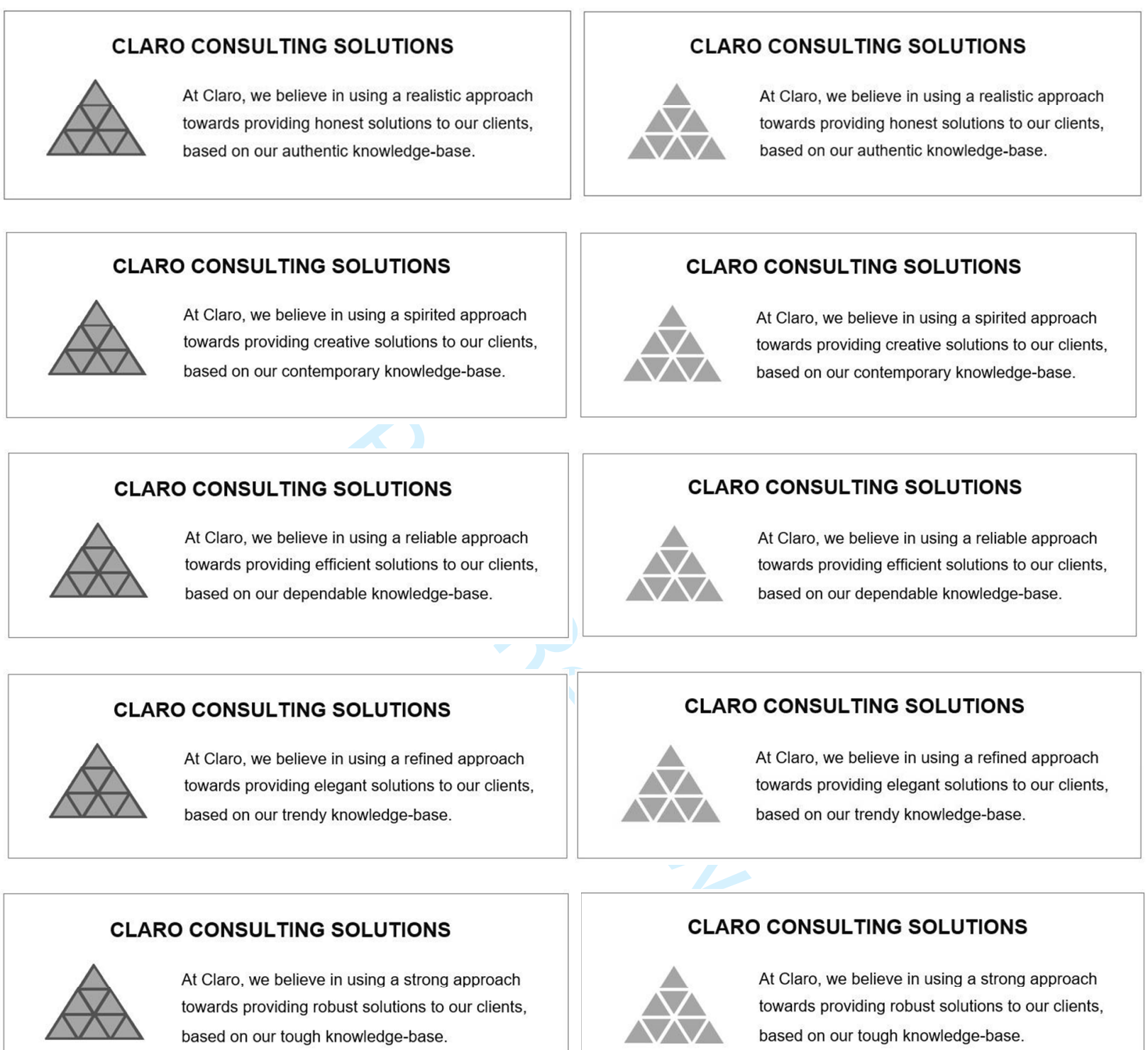

\section{CLARO CONSULTING SOLUTIONS}

At Claro, we believe in using a strong approach towards providing robust solutions to our clients, based on our tough knowledge-base.

\section{CLARO CONSULTING SOLUTIONS}

At Claro, we believe in using a refined approach towards providing elegant solutions to our clients,

based on our trendy knowledge-base.

\section{CLARO CONSULTING SOLUTIONS}

At Claro, we believe in using a strong approach towards providing robust solutions to our clients, based on our tough knowledge-base. 